\title{
Sediments from stormwater drainage system as sorbents of organic and inorganic pollutants
}

\author{
Aleksandra Sałata ${ }^{1, *}$ and Lidia Dąbek ${ }^{1}$ \\ ${ }^{1}$ Kielce University of Technology, Department of Environmental, Geomatics and Energy \\ Engineering, aleja Tysiąclecia Państwa Polskiego 7, 25-314 Kielce, Poland
}

\begin{abstract}
The study presents the results of tests aimed at determining variations in concentrations of polycyclic aromatic hydrocarbons (naphthalene, acenaphthylene, acenaphthene, fluorene, phenanthrene, anthracene, fluoranthene, pyrene, benzo[a]anthracene, chrysene, benzo[b]fluoranthene, benzo[k]fluoranthene, benzo[a]pyrene, dibenzo[a,h]anthracene, benzo[g,h,i]perylene and indeno[1,2,3-c,d]pyrene) and heavy metals (copper, cadmium, chromium, nickel, lead and zinc) in the sediments from the stormwater sewer system. Results of this study were then compared to Polish regulations and established ecological screening values to determine their potential risk to environment. The results suggest that stormwater sediments are moderately contaminated with PAHs and heavy metals according to domestic regulations and highly contaminated according to ecological benchmarks.
\end{abstract}

\section{Introduction}

Water quality issues remain invariably at the centre of research and environmental protection institutions because of their importance for the functioning of ecosystems. Sediments accumulated in the aquatic environment (lakes, rivers, seas, stormwater and stormwater reservoirs) are a valuable source of information on the ecological state of the environment. The fact is that sediments are widely recognized as a place of deposition of chemical pollutants entering the aquatic environment and thus as an essential component of their circulation in nature. Despite this, the assessment of environmental threats using this tool still seems insufficient and still neglected [1,2]. Therefore, the assessment of the quality of sediment should not be overlooked in the improvement of the aquatic environment, especially since the recommendation of the Water Framework Directive (EU 2000/60/EC) for 2015 was the need to achieve good ecological and chemical water status.

One of the components of the water environment functioning within the urban agglomerations is the sediment accumulating in various elements of the rain drainage system: in sewers, wells, street inlets and settlers located in the rainwater treatment plant assigned to each urban catchment. These sediments have a major influence on the processes running through the sewage system causing significant fluctuations of the charge in the inflow into the stormwater treatment plant in short periods of time. This transforms directly

\footnotetext{
*Corresponding author: asalata@tu.kielce.pl
} 
into the load of pollutants entering the treatment plant or overflow, and thus the receiver. Research conducted to determine the qualitative composition of sludge is used to determine the level of release of chemical impurities [3].

Sediment-forming matter consists of organic and mineral compositions and anthropogenic compounds. Such varied compositions are determined by the type of particles and their origin, transport processes and chemical and biochemical changes occurring in the water, sediment, and the boundary of these phases [4]. The composition of sediments, including the presence of organic matter, has a significant impact on their sorption capacity. These capacities and the influence of pollutants present in rain waters with slurry of grains, sand, gravel, plant remains and other sedimentation components of the solid phase forming the precipitate are possible due to the crystalline structure of the components, the presence of active functional groups predominantly in amorphous phases [5]. The composition of stormawter and of sediments accumulated in the system depends on many factors. Those include the type of the catchment management programme, the roadway system, the vehicular traffic volume, the occurrence of failures and environmental disasters, the frequency and manner of cleaning of the catchment (roads, squares) surface, the application of de-icing agents during winter months, parameters of atmospheric precipitation, season of the year, the sewer system hydraulics and structure and its facilities (separators, sedimentation tanks, street gullies, and sumps), the way of the sewer system operation, and also the fraction green belts constitute in the drained area. Sediments may hamper the flow of stormwater and they also can increase the pollutant load transported to the stormwater treatment plant, stormwater overflow structures, or directly to the receivers, where they create a major hazard to the biosphere and the adjacent land environments. Due to the chemical and biochemical processes, a part of pollutants may migrate to the waters again [6]. The most commonly occurring impurities in water sediments are heavy metals and polycyclic aromatic hydrocarbons (PAHs). In the aquatic environment, heavy metals can occur in two basic forms, they can either be solved, or bound to the solid phase particles. Metal occurrence in either of those forms depends on many factors including: the chemical form of metals delivered to the aquatic ecosystem, conditions prevailing in the liquid phase $(\mathrm{pH}$, redox potential, temperature, biological activity), surface reactivity, and grain composition of the solid phase. Tests on aquatic sediments are very often conducted to assess the environmental pollution with heavy metals, because after they get into the stormwater, a majority of them migrate to the sediments. In polluted aquatic sediments, elevated concentrations of cadmium, chromium, copper, nickel, zinc or lead are found most often. Their presence in the aquatic environment may result both from natural processes occurring in the atmosphere, which provides a dispersed source of pollutants, and from anthropogenic processes (transportation, industries, mining, municipal and industrial sewage, and also agriculture) which constitute point emission sources [7-9]. Polycyclic aromatic hydrocarbons are on the list of the most dangerous substances, which was compiled by the American Environmental Protection Agency (EPA). The list is updated and adjusted to the environmental conditions in many countries [10]. Polycyclic aromatic hydrocarbons are commonly classified into one of two groups based on their molecular structure. Low molecular weight (LMW) PAHs have three or fewer aromatic rings, while high molecular weight (HMW) PAHs have four or more rings. Differences in the structure and size of individual PAHs result in substantial variability in the physical and chemical properties of these substances. The toxicity of PAHs depends on a number of factors, including the species, route of exposure, and molecular structure of the PAH. In general, LMW-PAHs are considered to be acutely toxic and noncarcinogenic to aquatic organisms, whereas, HMW-PAHs are generally not acutely toxic to aquatic organisms, but a number of them are carcinogenic [11]. 
In the literature on bottom sediments and stormwater sediments, the geochemical criterion is used to assess the degree of pollution. The criterion is one of the chemical methods of evaluating the sediment quality. Chemical methods utilise the content of trace elements and chemical properties of sediments, which determine the potential capacity of sediments to bind toxic components, or the mobilisation of the latter from sediments. The criterion involves the comparison of the pollutant content in the sediment with that found in natural or low-polluted sediments, which provides the so-called geochemical background. Recent years have witnessed developments in ecotoxicological investigations methods for the aquatic environment, and also in assessing the hazards related to pollutant occurrence in water bodies receiving wastewater and surface runoff. In many countries, ecotoxicological criteria have entered legislation on sewage and hazardous wastes. Numerous methods have been developed to determine quality standards for bottom sediments. Sediment Quality Guidelines (SQGs) are based on both chemical and biological aspects. Poland still lacks legal regulations on the assessment of the harmful effect of chemical compounds in water sediments for the organisms that inhabit this environment. Many approaches have been made to establish SQGs. They rely on different theoretical or empirical basis used to assess the hazard posed by the presence of organic compounds and heavy metals in bottom sediments. The most widely used are TEL and PEL parameters, which are components of the empirical method applied to benthic organisms. The TEL, Threshold Effects Level, specifies the upper limit of pollutant concentration range, below which the harmful effect on aquatic organisms is found relatively seldom. The PEL, Probable Effects Level, is defined as the lower limit of pollutant concentration, which may significantly adversely affect the living organisms [12-15].

Sediment classification proposed by Bojakowska [16] incorporates ecotoxicological parameters TEL and PEL used in the USA and Canada. Sediments are categorised in a four-level scale, where: I. Unpolluted sediments (none of the harmful component content exceeds the TEL parameter), II. Low-polluted sediments (the content of at least one harmful component is higher than the TEL parameter, the content of all components is lower than the PEL parameter) III. Polluted sediments (the content of at least one harmful component exceeds the limit of Class II). IV. Strongly-polluted sediments (the content of at least one harmful component exceeds the limit of Class III). Sediments categorised as Class I and Class II can be freely applied to both aquatic and land environments. They are most often used as soil fertilisers, or to restore damaged banks of water reservoirs and rivers. Class III sediments can be relocated to designated sites and managed to a limited extent. Due to the elevated concentrations of hazardous compounds, those can be applied to industrial crops, or may be excluded from agricultural use. Strongly-polluted Class IV sediments should be treated before they are placed in the environment, or they should be stored at protected refuse sites under controlled conditions.

\section{Materials and methods}

\subsection{Study site and sampling}

The sampling stations including of four sedimentation tanks located in the urban area of Kielce city were studied. The facilities have different construction, operating time and land use. The largest and the oldest is the Piekoszowska catchment S1 (open tank) representing a wide range of land uses including both low - and high - density residential areas, industrial areas and agricultural, partly forested ones. The three other catchments are classified as typically industrial - the Jesionowa facility S2 (closed tank), and typically residential - the Witosa facility S3 (open tank) and the Kaczmarka facility S4 (closed tank) (Table 1). 
Table 1. Main technical parameters of catchments selected to study.

\begin{tabular}{|l|c|c|c|c|}
\hline \multicolumn{1}{|c|}{ Parameter } & S1 & S2 & S3 & S4 \\
\hline Construction year & 1992 & 2001 & 2003 & 2002 \\
\hline Tank type & open & closed & open & closed \\
\hline Total catchment area (ha) & 804.6 & 383.9 & 132.0 & 224.0 \\
\hline Residential area (\%) & 63 & 33 & 89 & 78 \\
\hline Industrial area (\%) & 9 & 65 & 0 & 14 \\
\hline Meadows, agricultural area (\%) & 27 & 0 & 0 & 0 \\
\hline Forests (\%) & 1 & 1 & 0 & 0 \\
\hline Green areas (\%) & 0 & 1 & 11 & 8 \\
\hline
\end{tabular}

The sediment samples were collected during winter season 2015, in accordance with the PN-EN ISO 5667-15:2009 standard method [17]. Samples were collected using a stainless steel standard bottom grab sampler or Eijkelkamp equipment for sites with difficult access, and placed in acid-washed plastic containers $(\sim 1 \mathrm{~L})$. Between the series of sample collecting, all equipment was rinsed with water from the reservoir. Then, the samples were transported to the laboratory and homogenized using a solvent-cleansed stainless steel bucket and a spoon. The physical and chemical parameters were measured immediately afterwards.

\subsection{Analytical techniques}

The $\mathrm{pH}$ and temperature were measured promptly after samples homogenization in accordance with the PN-EN 12176:2004 method using SevenMulti ${ }^{\mathrm{TM}}$ meter (Mettler Toledo) [18]. Organic content, measured as a loss of ignition (LOI), was determined in accordance with the PN-78/C-04541 method [19], which involved drying the sediment at $105^{\circ} \mathrm{C}$ to a constant weight, and then heating it at $550^{\circ} \mathrm{C}$ for $2 \mathrm{~h}$. Sediment samples of $0.2 \mathrm{~g}$ were mineralized in $7 \mathrm{ml}$ nitric acid using microwave oven (Multiwave 3000, Anton Paar). Concentrations of heavy metals: cadmium, copper, chromium, nickel, lead and zinc were determined by atomic emission spectrometry with inductively coupled plasma ICP Optima 8000 (Perkin Elmer) with certified multi element standards. Sediment samples with a mass of $1 \mathrm{~g}$ were extracted in dichloromethane to determine the total sum of PAHs. These compounds are grouped in two categories based on their molecular weights and these are low and high. Low Molecular Weight PAHs (LMW) containing two- and three-rings with molecular weight from $152 \mathrm{~g} \cdot \mathrm{mol}^{-1}$ to $202 \mathrm{~g} \cdot \mathrm{mol}^{-1}$ include: naphthalene (NAPT), acenaphthylene (ACNY), acenaphthene (ACEN), fluorene (FLUR), phenanthrene (PHEN) and anthracene (ANTH). The High Molecular Weight (HMW) PAHs have four-rings to seven-rings with molecular mass ranging from $228 \mathrm{~g} \cdot \mathrm{mol}-1$ to $278 \mathrm{~g} \cdot \mathrm{mol}-1$ include: fluoranthene (FLTH), pyrene (PYR), benzo[a]anthracene (B(a)A), chrysene (CHRY), benzo[b]fluoranthene $(\mathrm{B}(\mathrm{b}) \mathrm{F})$, benzo[k]fluoranthene $(\mathrm{B}(\mathrm{k}) \mathrm{F})$, benzo[a]pyrene $(\mathrm{B}(\mathrm{a}) \mathrm{P})$, dibenzo[a,h]anthracene $(\mathrm{D}(\mathrm{ah}) \mathrm{A})$, benzo[g,h,i]perylene $(\mathrm{B}(\mathrm{ghi}) \mathrm{P})$, and indeno[1,2,3$\mathrm{c}, \mathrm{d}]$ pyrene (INPY). Concentrations of PAHs were identified in samples in accordance with the PN-EN 15527:2008 method [20]. To determine the reliability of the PAH data, including the efficiency of extraction methods and interferences that may be introduced during sample preparation, deuterated internal standards were used (d-8 NAPHT and d-12 B(a)A). These standards ensure that the accuracy of the results obtained is independent of the recovery degree. The next step included wetting the sediment sample with acetone, 
adding acetone with deuterated standards, intensive stirring of the sample and undisturbed evaporation of the acetone. This procedure makes it possible to achieve a similar binding form between standards added and the sediment matter. All PAH concentrations were reported on a dry weight basis.

\section{Results and discussion}

The mean of $\mathrm{pH}$, content of mineral (SM) and organic matter described as a loss of ignition (LOI) together with moisture content were measured in the sediment samples. The $\mathrm{pH}$ values ranged $7.14 \div 7.30$ and were comparable with those of silts from inland water bodies, in which about neutral $\mathrm{pH}$ conditions $(6.5 \div 7.5)$ are maintained. Sediments were characterised by a high moisture content of $78 \% \div 86 \%$, mineral matter content up to $97 \%$, and organic matter content ranging from $3 \%$ to $5 \%$.

The content of heavy metals (zinc, cadmium, chromium, nickel, lead and copper) in the sediments from the each site geochemical classification are presented in Table 2. The data indicate that the sediments of concern showed varied metal content. The highest average concentrations were recorded for zinc. The zinc content ranged from $127.4 \mathrm{mg} \cdot \mathrm{kg}^{-1}$ for S4 site, to $375.6 \mathrm{mg} \cdot \mathrm{kg}^{-1}$ for S1 site. The lead content comparable in every location at level $\sim 70$ $\mathrm{mg} \cdot \mathrm{kg}^{-1}$. The concentrations of other metals were markedly lower. In general, the highest concentrations were recorded for the tank S1, which is the most contaminated. Comparing the results of tests on metal concentrations in the analysed sediments with the quality standards for soil and land stipulated in the Regulation of the Minister of Environment [21], it can be stated that concentrations of all examined heavy metals are much lower than the permissible values for urbanised areas categorised as Group B. In accordance with the regulation, the concentrations range as follows, for zinc: $300-720 \mathrm{mg} \cdot \mathrm{kg}^{-1}$, cadmium: 4 $10 \mathrm{mg} \cdot \mathrm{kg}^{-1}$, lead: $100-200 \mathrm{mg} \cdot \mathrm{kg}^{-1}$, copper: $100-200 \mathrm{mg} \cdot \mathrm{kg}^{-1}$, nickel: $50-210 \mathrm{mg} \cdot \mathrm{kg}^{-1}$ and chromium: $150-380 \mathrm{mg} \cdot \mathrm{kg}^{-1}$.

Table 2. Heavy metal concentrations in sediments compared with local background values. Geochemical assessment of stormwater sediments wg Bojakowska [16]

\begin{tabular}{|l|c|c|c|c|c|c|c|c|}
\hline Metal & S1 & S2 & S3 & S4 & Class I & Class II & Class III & Class IV \\
\hline \multicolumn{9}{|c|}{$\mathrm{mg} \cdot \mathrm{kg}^{-1}$} \\
\hline Zinc & $\mathbf{3 7 5 . 6}$ & $\mathbf{2 2 1 . 2}$ & $\mathbf{1 9 9 . 5}$ & $\mathbf{1 2 7 . 4}$ & 125 & 300 & 1000 & $>1000$ \\
\hline Cadmium & 0.1 & 0.2 & 0 & 0 & 0.7 & 3.5 & 6 & $>6$ \\
\hline Chromium & $\mathbf{5 6 . 8}$ & 40.3 & 31.1 & 24.3 & 50 & 100 & 400 & $>400$ \\
\hline Nickel & 13.85 & 14.8 & 11.55 & 9.2 & 16 & 40 & 50 & $>50$ \\
\hline Lead & $\mathbf{8 5 . 0 5}$ & $\mathbf{9 9 . 1 5}$ & $\mathbf{6 1 . 6 5}$ & $\mathbf{8 8 . 7}$ & 30 & 100 & 200 & $>200$ \\
\hline Copper & $\mathbf{3 9 . 8}$ & $\mathbf{4 7 . 2}$ & $\mathbf{3 8 . 1 5}$ & $\mathbf{4 5 . 8}$ & 20 & 100 & 300 & $>300$ \\
\hline
\end{tabular}

As regards cadmium, chromium and nickel for sites S2, S3 and S4 respectively, the sediments were classified as unpolluted belonging to Class I. With respect to the content of zinc, however, the sediments were categorised as Class II in every case, except location S1 - where sediments were assigned to class number III . Taking into account geochemical parameters, the whole tested material can be considered medium-polluted, i.e. the sediments may pose an immediate hazard to the aquatic environment and the organisms living there. Elevated concentrations of heavy metals may result from many processes that occur in the aquatic environment, to a large extent, they depend on sediment composition, thus on the character of the catchment.

The total content of PAHs with geochemical assessment in the examined sediments was presented in Table 3 . The highest concentrations of polycyclic aromatic hydrocarbons were observed in sediment samples from S4 site and the lowest for S1 site $-83.40 \mathrm{mg} \cdot \mathrm{kg}^{-1}$ 
and $39.30 \mathrm{mg} \cdot \mathrm{kg}^{-1}$, respectively. Comparing the results with the standards on soil and land quality [21], the values reported were below the permissible ones, specified as $200 \mathrm{mg} \cdot \mathrm{kg}^{-1}$. Consequently, the sediments do not pose a hazard to the natural environment. However, in addition to the total content, also the content of individual PAH compounds was taken into account. The material of concern was categorised as Class IV - for all samples. As regards Class IV, i.e. strongly polluted sediments, it is recommended that they should be treated before they are disposed of into the environment. Otherwise, they should be stored at protected refuse sites under controlled conditions.

Table 3. PAHs concentrations in sediments compared with local background values.

Geochemical assessment of stormwater sediments wg Bojakowska [16]

\begin{tabular}{|c|c|c|c|c|c|c|c|c|c|}
\hline PAH & S1 & S2 & S3 & S4 & Class I & Class II & Class III & Class IV \\
\hline \multicolumn{9}{|c|}{$\mathrm{mg}^{\prime} \mathrm{kg}^{-1}$} \\
\hline ACEN & 0.22 & $\mathbf{0 . 5 5}$ & 0.22 & 0.44 & 0.01 & 0.1 & 0.5 & $>0.5$ \\
\hline ACNY & $\mathbf{2 . 2 0}$ & $\mathbf{2 . 9 7}$ & $\mathbf{3 . 1 9}$ & $\mathbf{1 3 . 3 1}$ & 0.01 & 0.15 & 0.5 & $>0.5$ \\
\hline PHEN & $\mathbf{7 . 1 5}$ & $\mathbf{1 0 . 8 9}$ & $\mathbf{6 . 6 0}$ & $\mathbf{8 . 3 6}$ & 0.05 & 0.5 & 1 & $>1$ \\
\hline FLTH & $\mathbf{1 4 . 6 3}$ & $\mathbf{1 5 . 6 2}$ & $\mathbf{1 2 . 1 0}$ & $\mathbf{2 6 . 6 2}$ & 0.1 & 1.5 & 3 & $>3$ \\
\hline FLUR & $\mathbf{0 . 8 1}$ & $\mathbf{2 . 4 2}$ & $\mathbf{0 . 9 2}$ & $\mathbf{1 . 9 6}$ & 0.02 & 0.15 & 0.5 & $>0.5$ \\
\hline ANTH & $\mathbf{1 . 7 3}$ & $\mathbf{2 . 0 7}$ & 0.81 & $\mathbf{5 . 2 9}$ & 0.05 & 0.25 & 1 & $>1$ \\
\hline PYR & $\mathbf{1 2 . 7 7}$ & $\mathbf{1 4 . 0 3}$ & $\mathbf{1 0 . 0 1}$ & $\mathbf{2 6 . 8 0}$ & 0.1 & 1.5 & 2.5 & $>2.5$ \\
\hline CHRY & 0.92 & 1.15 & $\mathbf{4 . 6 0}$ & 1.84 & 0.1 & 0.75 & 2.8 & $>2.8$ \\
\hline B(a)A & 0.58 & 1.15 & 0.69 & 0.58 & 0.1 & 0.7 & 1.6 & $>1.6$ \\
\hline B(b)F & 0.92 & 1.50 & $\mathbf{6 . 3 3}$ & 2.42 & 0.1 & 0.75 & 3 & $>3$ \\
\hline B(k)F & 0.12 & 0.69 & 2.19 & 1.15 & 0.1 & 0.75 & 3 & $>3$ \\
\hline B(a)P & 0.92 & 1.15 & $\mathbf{5 . 8 7}$ & $\mathbf{1 . 7 3}$ & 0.1 & 0.75 & 1.6 & $>1.6$ \\
\hline D(ah)A & 0.00 & $\mathbf{0 . 8 1}$ & $\mathbf{2 . 3 0}$ & $\mathbf{0 . 4 6}$ & 0.01 & 0.15 & 0.25 & $>0.25$ \\
\hline B(ghi)P & $\mathbf{0 . 5 8}$ & $\mathbf{1 . 0 4}$ & $\mathbf{2 . 4 2}$ & $\mathbf{1 . 3 8}$ & 0.05 & 0.2 & 0.4 & $>0.4$ \\
\hline INPY & $\mathbf{0 . 5 8}$ & $\mathbf{0 . 8 1}$ & $\mathbf{4 . 2 6}$ & $\mathbf{1 . 3 8}$ & 0.05 & 0.2 & 0.4 & $>0.4$ \\
\hline LPAHs & $\mathbf{3 9 . 3 0}$ & $\mathbf{5 0 . 6 0}$ & $\mathbf{5 5 . 2 0}$ & $\mathbf{8 3 . 4 0}$ & 1 & 7.5 & 15 & $>15$ \\
\hline
\end{tabular}

\section{Conclusion}

The sediments accumulated in the stormwater sewer system cause problems that are related not only to the system operation, but also to the hazard they may pose when delivered to the receiver. Because of their properties, the sediments are characterised by a high affinity for accumulating and storing toxic pollutants in their structure, such as heavy metals and also organic compounds like polycyclic aromatic hydrocarbons. The results of tests show significant differences in the physico-chemical composition of the sediments of concern. As expected, the analysis of the pollutant content revealed the occurrence of heavy metals, namely zinc, cadmium, chromium, nickel, lead and copper, and also of polycyclic aromatic hydrocarbons. The results describing metal concentrations in the sediments were referred to the soil and land quality standards stipulated in the Regulation of the Minister of Environment. The comparison shows that the concentration values of all analysed heavy metals are much lower than the permissible values for urbanised areas. In accordance with the geochemical classification, however, the sediments of concern were categorised as Class I or in some cases class II, that is low-polluted. Consequently, they may pose an immediate hazard to the aquatic system and the organisms inhabiting it. The analysis of the content sum of PAH organic compounds shows high concentrations of those substances 
from $39.30 \mathrm{mg} \cdot \mathrm{kg}^{-1}$ to $83.40 \mathrm{mg} \cdot \mathrm{kg}^{-1}$, which indicates their accumulation in the examined sediments. Comparing the test results with the soil and land quality standards, it can be concluded that, as it was the case for heavy metals, the values are lower than the permissible ones, i.e. $200 \mathrm{mg} \cdot \mathrm{kg}^{-1}$. As a result, the sediments can be considered as not causing any environmental hazard. Detailed geochemical assessment of the stormwater sediments, however, indicates a different classification. Sediments are categorised as Class $\mathrm{IV}$, i.e. strongly polluted, which means it is recommended to treat them before disposal into the environment or to store them at protected refuse sites under controlled conditions.

The work reported herein was undertaken as part of the statutory project No. 05.0.10.00/2.01.01.01.0026 (MNSP.IKTW.15.001).

\section{References}

1. E. Daly, P.M. Bach, A. Deletic. Adv Water Resour., 74, 148-155, (2014)

2. J.V. Loperfido, G. B. Noe, S. T. Jarnagin, D. M. Hogan. J Hydrol., 519, 2584-2585 (2014)

3. A. Jlilati, K. Jaromin, M. Widomski, G. Łagód. Proceedings of ECOpole, 3(1), 147152 (2009)

4. E. Szalińska. Role of bottom sediments in the assessment of the quality of continental waters environment Publishing house of Cracow University of Technology, Monograph 396, (2011) (in Polish)

5. M. Gdaniec-Pietryka. Physical speciation and the mobility of analytes from polycyclic aromatic hydrocarbons and polychlorinated biphenyls on the bottom sediment-water phase boundary (in Polish). Doctoral thesis. Faculty of Chemistry, Gdansk University of Technology, Department of Analytical Chemistry, (2008) (in Polish)

6. J. Królikowska, A. Królikowski. Rainwater. Disposal, management, pre-treatment and use. Seidel - Przywecki Publishing house, (2012) (in Polish)

7. D. Foster, S. M. Charlesworth. Hydrol Process., 10, 227-261, (1996)

8. A. El-Mufleh, B. Béchet, I. Basile-Doelsch, C. Geffroy-Rodier, A. Gaudin, V. Ruban. Envirol Sci Pollut Res, 21, 9764-9776 (2014)

9. P. Bigus, M. Tobiszewski, J. Namieśnik. Mar Pollut Bull., 78, 26-42, (2014)

10. X. Yuan, L. Zhang, L. Li, C. Wang, J. Ji. Catena, 119, 52 - 60, (2014)

11. J.L. Bertrand-Krajewski, C. Becouze, A. Dembélé, M. Coquery, C. Cren-Olivé, B. Barillon, P. Dauthuille, J. Chapgier, M. Grenier-Loustalot, P. Marin. Proceedings of the 11th International Conference on Urban Drainage, (2008)

12. POLYCYCLIC AROMATIC HYDROCARBONS (PAHs), Canadian Sediment Quality Guidelines for the Protection of Aquatic Life, Canadian Environmental Quality Guidelines Canadian Council of Ministers of the Environment, (1999)

13. Bojakowska I., Gliwicz T., Małecka K. Results of geochemical tests on Poland's aquatic sediments in the years 2003-200. Inspection of Environmental Protection. Warsaw (2006) (in Polish)

14. Bojakowska I., Sokołowska G. Geochemical classes of aquatic sediment purity. Polish Geological Review. 46 (1), 49-54, (1998) (in Polish)

15. D.D. McDonald, C.G. Ingersoll, T.A. Berger. Arch Environl Con Tox., 39, (2000)

16. I. Bojakowska. Criteria of evaluation of pollution of aquatic sediments. Polish Geological Review, 49, nr 3, (2001) (in Polish) 
17. PN-EN ISO 5667-15:2009. Water quality. Sampling. Part 15: Guidance on the preservation and handling of sludge and sediment samples (in Polish)

18. PN-EN 12176:2004. Characterisation of Sludge. Determination of $\mathrm{pH}$ value (in Polish)

19. PN-78/C-04541. Water and Wastewater. Determination of Dry Residue, Residue on Ignition, Loss on Ignition and Dissolved Substances, Dissolved Mineral Substances and Dissolved Volatile Substances (in Polish)

20. PN-EN 15527:2008. Characterisation of Waste. Determination of Polycyclic Aromatic Hydrocarbons (PAH) in Waste Using Gas Chromatography Mass Spectrometry (GC/MS) (in Polish)

21. Regulation of the Minister of Environment of 9 September 2002 on soil and land quality standards, Journal of Laws, No. 165, item 1359, (2002) (in Polish) 